\title{
ÉTICA E DIREITOS HUMANOS NA EDUCAÇÃO: O QUE OS ESTUDOS DE GÊNERO TÊM A VER COM ISSO?
}

\author{
ETHICS AND HUMAN RIGHTS IN EDUCATION: WHAT DOES GENDER \\ STUDIES HAVE TO DO WITH IT?
}

\author{
ÉTICA Y DERECHOS HUMANOS EN LA EDUCACIÓN: ¿QUÉ LOS \\ ESTUDIOS DE GÉNERO TIENEN VER CON ESO?
}

\section{Eliane Cadoná ${ }^{1}$ Sabrina Koch ${ }^{2}$}

\begin{abstract}
RESUMO
No presente artigo, trazemos à tona a importância da articulação entre Direitos Humanos e os Estudos de Gênero no contexto da Educação Formal. Tal problematização engloba, sob nosso ponto de vista, um movimento ético-estético-político necessário para o cenário atual, e para uma Educação comprometida com a realidade das pessoas que dela se beneficiam. Na ideia de que construímos e somos construídos por intermédio das relações, e que inventamos e damos sentido ao mundo por intermédio da linguagem, propomos um olhar interdisciplinar e problematizador em meio às práticas de sala de aula. A noção de cidadania, nesse cenário, ganha centralidade, e exercita uma prática de formação integral, sensível e incentivadora das diversidades e do cuidado em prol da emergência de modos singulares de existir.
\end{abstract}

PALAVRAS-CHAVE: Estudos de Gênero. Direitos Humanos. Educação.

\section{ABSTRACT}

In this article, we bring up the importance of the articulation between Human Rights and Gender Studies in the Formal Learning context. Such problematization includes, from our point of view, an ethicalaesthetic-political movement necessary for the current scenario, and for an Education committed to the reality of the people who benefit from it. In the idea that we build and are built through relationships, and that we invent and give meaning to the world through language, we propose an interdisciplinary and problematizing view amid classroom pra ctices. The notion of citiz enship gains central position in this scenario, and exercises a comprehensive training practice that is sensitive and encouraging of diversities, and care for the emergence of unique ways of existing.

KEYWORDS: Gender Studies. Human Rights. Education.

\section{RESUMEN}

En el presente artículo, traemos a la superficie la importancia de la articulación entre Derechos Humanos y los Estudios de Género en el contexto de la Educación Formal. Tal problematización engloba, desde nuestro punto de vista, um movimiento ético-estético-político necesario para el escenario actual, y para uma Educación comprometida con la realidad de las personas que de ella se benefician. En la idea de que construimos y somos construidos por intermedio de las relaciones, y que inventamos y damos sentido al mundo por intermedio del lenguaje, proponemos uma mirada interdisciplinaria y problematizadora en medio de las prácticas de clase. La noción de ciudadanía, en ese escenario, gana centralidad, y ejercita

\footnotetext{
1 Doutora em Psicologia (PUCRS). Professora do Programa de Pós-Graduação em Educação da Universidade Regional Integrada do Alto Uruguai e das Missões - Câmpus de Frederico Westphalen. Email: eliane@uri.edu.br.

${ }^{2}$ Mestre em Psicologia (PUCRS). Professora da Universidade Regional Integrada do Alto Uruguai e das Missões - Câmpus de Frederico Westphalen. E-mail: koch@uri.edu.br.

\begin{tabular}{l|l|l}
\hline Rev. Ciências Humanas & Frederico Westphalen, RS & Jan./abr. 2019 \\
\hline
\end{tabular}

\begin{tabular}{l|l|l} 
Recebido em: $15 / 04 / 2019$ & Aceito em: 29/04/2019 & Pg. 130 - 145
\end{tabular}
}




\section{(1) URI|}

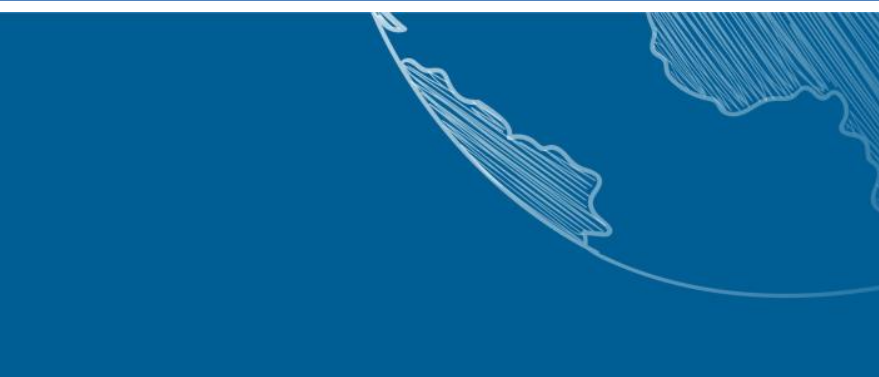

una práctica de formación integral, sensible e incentivadora de las diversidades y del cuidado en pro de la emergencia de modos singulares de existir.

PALABRAS CLAVE: Estudios de Género. Derechos Humanos. Educación.

\section{CONSIDERAÇÕES INICIAIS}

Este artigo é fruto de investigações no campo da pesquisa, junto ao Curso de Psicologia e ao Programa de Pós-Graduação em Educação da URI - Câmpus de Frederico Westphalen, cujos objetivos propõem-se investigar discursos de gênero e saúde em Políticas Públicas da Educação Formal brasileira e em meio às práticas discursivas de professores/as da Educação Básica.

Os Estudos de Gênero têm sido evidenciados, no atual cenário governamental, por vezes de forma equivocada e desprovida de leitura científica. Se, por um lado, muitos/as se autorizam a proferir verdades sobre o assunto, a Escola, em nossas práticas, enquanto professoras e psicólogas, têm sido retratada pela carência dos/as educadores/as em relação a como trabalhar aspectos como Gênero, Diversidade Sexual e Direitos Humanos, em uma perspectiva ampliada, e que condiga com as teorias mais recentes do campo das ciências e o que preconiza, em sua essência, a Lei de Diretrizes e Bases da Educação brasileira (BRASIL, 1996), bem como os documentos posteriores a ela (BRASIL, 1997; BRASIL, 2013; BRASIL, 2017).

Se, por um lado, transbordam argumentos que atrelam os Estudos de Gênero a ideias contrárias ao projeto de lei Escola sem Partido (projeto de lei número 6583/13), por outro urge a necessidade de pesquisadores/as estudiosos/as da área instrumentalizar a Educação Básica dentro dessa perspectiva de gênero, que não se resume a conceitos e verdades pré-determinadas, mas sim a um conjunto de problematizações e teorias que resultam em um campo interdisciplinar de saber, diretamente ligada à realidade das pessoas e à lógica do pensamento pós-moderno. Falamos aqui em pensamento pósmoderno inspiradas em Boaventura de Sousa Santos (1988), e à noção de que o mesmo configura-se em uma tentativa de ruptura com a lógica da modernidade de fragmentar os conhecimentos, hierarquizá-los, fazendo da ciência um movimento "racional", "neutro e "objetivo". Acreditamos, inspiradas no autor, que o exercício de pensar fora \begin{tabular}{l|l|l}
\hline Rev. Ciências Humanas & Frederico Westphalen, RS & Jan./abr. 2019 \\
\hline
\end{tabular}

\begin{tabular}{l|l|l} 
Recebido em: $15 / 04 / 2019$ & Aceito em: 29/04/2019 & Pg. 130 - 145 \\
\hline
\end{tabular}




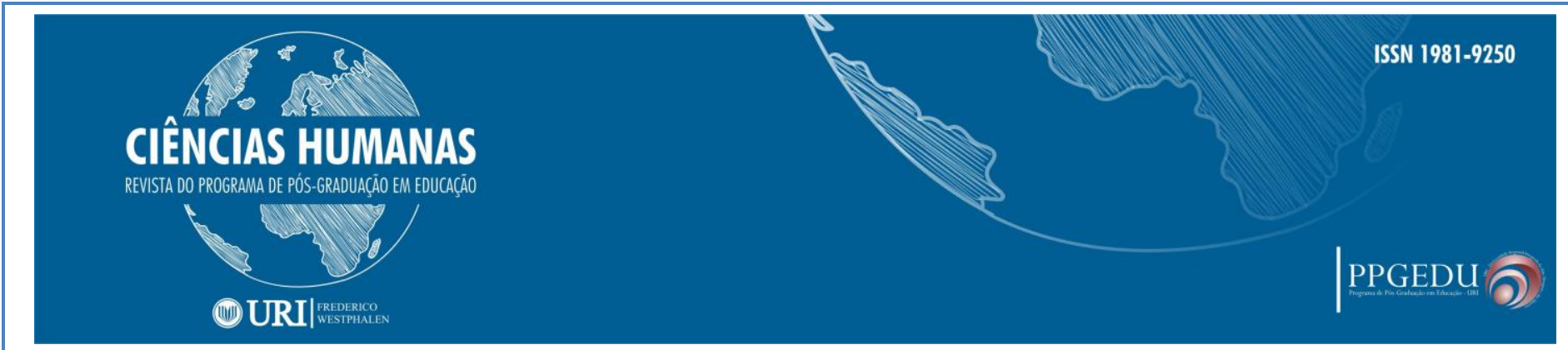

dessa lógica constitui-se em uma articulação e consideração dos diferentes saberes (científicos ou não) no exercício de uma ciência que respeite as características do campo que analisa, e que compreende que os fenômenos humanos estão marcados também pela subjetividade, pela implicação de quem os analisa e pelos afetos e sentimentos que o construíram.

Além disso, em tempos como o que vivemos, é papel da Universidade promover uma discussão diferente daquela cultuada no senso comum, com fins de ampliar o olhar sobre as diferenças, ou ainda, e melhor, problematizar o que entendemos e delimitamos enquanto "diferença". Corroborando com Candau (2012), compreendemos que urge a necessidade de superação de uma escola moderna que exclui, porque entende, equivocadamente, que a ideia de inclusão atrela-se à noção de uniformização de práticas, de modos de existir e pensar.

A autora articula ainda a noção de uma Escola que inclui diretamente ligada ao reconhecimento de que as diferenças devem ser reconhecidas e respeitadas, e não apagadas. O/a aluno/a vem para a escola com uma bagagem recheada de conteúdo, incluindo culturas, individualidades, classes sociais, identidades... Atento a isso, o processo de ensino-aprendizagem deve considerar tais fatores como parte integrante no cotidiano escolar que, articulado aos conteúdos trabalhados, transformam o ato de aprender e ensinar em uma experiência única, um processo singular e em constante devir.

Para iniciarmos a apresentação das bases epistemológicas do nosso estudo, destacamos que, a partir de uma perspectiva construcionista, compreendemos que a realidade e as verdades se constroem pelas pessoas e por intermédio das relações que estabelecem com o mundo, consigo mesmas, com seus pares, grupos, sociedade, história e contexto em que existem (GERGEN, 2008; 1985/2009; GERGEN; GERGEN, 2010). Assim, reconhecemos e corroboramos com a noção de que a pesquisa não se constitui em uma prática neutra, haja vista, já de início, a sempre transversalizada visão de sujeito e de mundo, provinda daquele/a que a formula.

Assim, reconhecemos também que essa discussão é, de fato, um movimento ético, político e estético, encharcado de comprometimento com o lugar que ocupamos

\begin{tabular}{l|l|l} 
Recebido em: 15/04/2019 & Aceito em: 29/04/2019 & Pg. 130 - 145
\end{tabular}




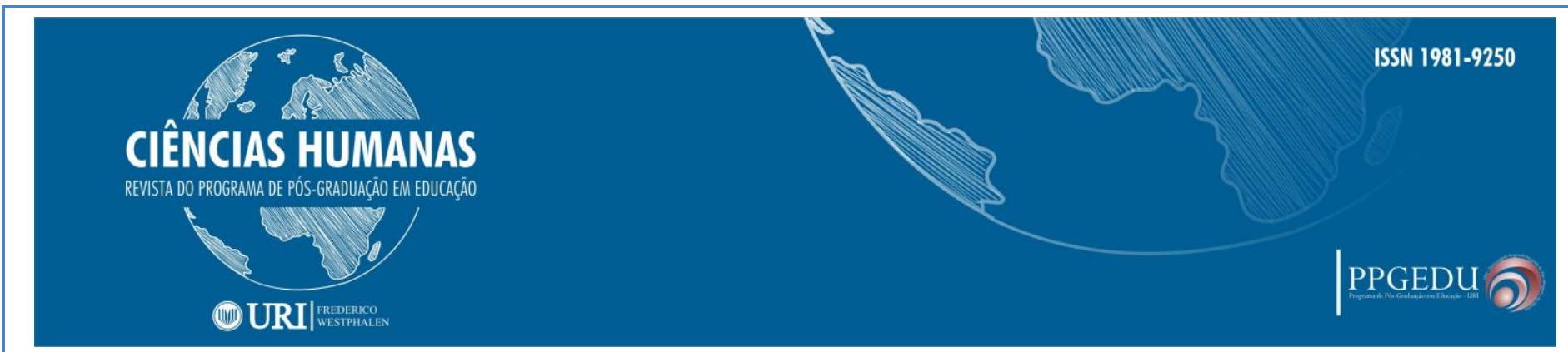

na sociedade e com todos os atravessamentos institucionais (linguagem, saúde, mídia, justiça, educação...) que perpassam o modo de olhar para nós mesmos/as e para o nosso entorno. Isso porque nosso intuito é deixar claro que partimos de um lugar, de um modo de compreender as questões morais que nos cercam e que, por ser tal olhar um processo, está muito mais próximo à ideia de uma obra de arte do que de um conceito fechado, de uma verdade absoluta. É também um movimento político, porque apropria-se de determinados discursos e, a partir deles, firma-se em uma tentativa de desacomodar o/a leitor/a (GUATTARI, 1990).

É válido destacar aqui que, por ética, compreendemos um exercício de problematização constante a respeito do que tomamos como certo e errado, bom e ruim (GUARESCHI, 2005). Assim, exercitar a ética é não apenas partir de um lugar que define preceitos morais, mas compreender a relação que estabelecemos com o mundo e com nós mesmos a partir desses preceitos. A ética, aqui, a partir da nossa leitura, desacomoda a moral, torna ela fluida, porque reconhece os processos históricos e singulares de cada tempo, lugar e circunstância e os discursivos que nos fazem compreender fenômenos e tomar suas compreensões enquanto verdades.

Com a adoção, por parte do Estado brasileiro, da ideia de que a Educação é um direito de todos e dever do Estado e de que as práticas nesse campo devem estar articuladas aos princípios da promoção de cidadania e do respeito à diversidade, esse campo passa a ser também espaço de protagonismo, possibilitador de formação de pensamento crítico e sensível às necessidades de seu contexto. A Escola, aqui, é mais um dentre tantos espaços onde essas perspectivas precisam ser colocadas em prática, tendo em vista a proposta de Educação Formal explicitada na Lei de Diretrizes e Bases (BRASIL, 1996), que atrela o ensino a práticas emancipatórios e com a participação de todos/as os/as atores/as envolvidos/as nesse cenário.

Os Estudos de Gênero, corroborando com as perspectivas acima destacadas, ao beberem de diferentes fontes de saber, permitem a problematização do cotidiano, além de discutir como questões ligadas à sexualidade e à identidade foram se configurando de acordo com modelos higienistas, carimbados pelo pensamento moderno, positivista e cartesiano de olhar para os fenômenos (BUTLER, 2008; COLLING, 2004; LOURO,

\begin{tabular}{l|l|l} 
Recebido em: $15 / 04 / 2019$ & Aceito em: 29/04/2019 & Pg. 130 - 145 \\
\hline
\end{tabular}




\section{CIÊNCIAS HUMANAS}

REVISTA DO PROGRAMA DE PÓS-GRADUAĞ̈O EM EDUCAĞ̄o

\section{(10)URI|}

2000; SALIH, 2013; STREY, 2012). Inspiram, ainda, a partir da leitura que temos desses estudos, uma provocação que interroga o modo como lemos e vivemos o mundo, nossas relações, nossos corpos e sentimentos. Reconhecem que fomos educados/as a olharmos para nossas sexualidades como se fôssemos todos/as iguais, e como se nossa anatomia falasse por si mesma, e que, portanto, pré-estabeleceria, assim que tivéssemos nosso sexo demarcado, nossas identidades, nossos desejos e formas de se apresentar ao mundo.

Com a Lei de Diretrizes e Bases (BRASIL, 1996), o Ministério da Educação e da Cultura automaticamente publica, em 1997, os PCNs (Parâmetros Curriculares Nacionais) (BRASIL, 1997). Nesse documento, pautado nos ideais da Constituição Federal de 1988, propõe-se as bases para uma educação articulada ao exercício da cidadania, com ênfase na criticidade e na construção de cidadãos e cidadãs protagonistas de sua formação. Além dos conteúdos oriundos de áreas tradicionais do conhecimento, o documento propõe a discussão, no contexto de sala de aula, de temas transversais como Saúde, Ética, Direitos Humanos e Orientação Sexual. Fernandes e Paludeto (2010) referem que tais reflexões apontam que a cidadania deve ser compreendida como produto de histórias sociais protagonizadas pelos grupos e, nesse processo, constituída por diferentes tipos de direitos e instituições.

Assim, temáticas como Direitos Humanos, Gênero e Ética passam a transversalizar os conteúdos trabalhados em sala de aula desde então, embora a formação do/a professor/a ainda continue, na visão deles/as, linear e baseada em fragmentação por conteúdos. Portanto, torna-se um desafio colocar em prática esse projeto, tendo em vista a ideia de, junto a ele, dar voz e vez a práticas cotidianas diferenciadas na escola (ainda tão moderna) e, com isso, agregar o conhecimento científico a essas narrativas para uma melhor implantação de ideais como respeito às diversidades.

Bernardi (2000) nos contextualiza sobre A Declaração Universal dos Direitos Humanos (1948), primeiro documento norteador da defesa de tais direitos, que surge após a Segunda Guerra Mundial, pelos grandes atos de violência cometidos contra a humanidade naquele cenário. Já no Brasil, tais atrocidades também se deram no período 


\section{CIÊNCIAS HUMANAS}

REVISTA DO PROGRAMA DE PÓS-GRADUAÇ̄OA EM EDUCAÇ̄̃O

\section{(1) URI|}

da Ditadura Militar (1964-1985). Pensando historicamente, podemos compreender que

Direitos Humanos é um tema extremamente recente em nosso país, visto que discussões começaram a existir após o retorno à condição democrática, a partir de 1988, em que os direitos propriamente sociais surgem com uma nova Constituição Federal (BRASIL, 1988). Assim, vale situar que:

Direitos Humanos são aqueles comuns a todos, a partir da matriz de direito à vida, sem distinção alguma decorrente de origem geográfica, caracteres do fenótipo (cor da pele, traços do rosto e cabelo), da etnia, nacionalidade, sexo, faixa etária, presença de incapacidade física ou mental, nível socioeconômico ou classe social, nível de instrução, religião, opinião política, orientação sexual ou de qualquer tipo de julgamento moral. São aqueles que decorrem do reconhecimento da dignidade intrínseca de todo ser humano (BENEVIDES, 2007, p. 337).

O Brasil, historicamente, é caracterizado por desigualdades, fundamentado num modelo neoliberal. Diante desse contexto, os direitos políticos partidários e os interesses de determinadas classes sobre outras sobrepõem-se aos direitos sociais, violando constantemente a dignidade humana. Diversos/as autores/as alertam para a condenação de milhões de homens, mulheres e crianças à marginalização ocasionadas pelos resultados do culto ao individualismo, ao consumismo e à competição (práticas com inspiração neoliberal), e tal realidade de violação à dignidade aponta a necessidade urgente de uma mudança na cultura de Direitos Humanos, para dar voz às questões marginalizadas na sociedade (CANDAU, 2000; BENEVIDES, 1998).

A discussão sobre Direitos Humanos no País e, especialmente, na Educação, seja no Ensino Superior ou na Educação Básica se faz necessária e não deve ser negligenciada, pela importância da formação de cidadãos/as críticos/as e abertos/as a reflexões sobre as condições sociais e políticas que vivenciam. É de caráter urgente ampliar nosso olhar acerca do humano, de sua natureza, cultura, princípios e condições/possibilidades de vida. Consideramos relevante ainda que a Escola esteja atenta não só ao educar para os Direitos Humanos, mas também ao educar para desconstruir as relações de gênero e de minorias que levam à exclusão e ao apagamento das diversidades como forma de manifestação das subjetividades (MACIEL, 2016). 


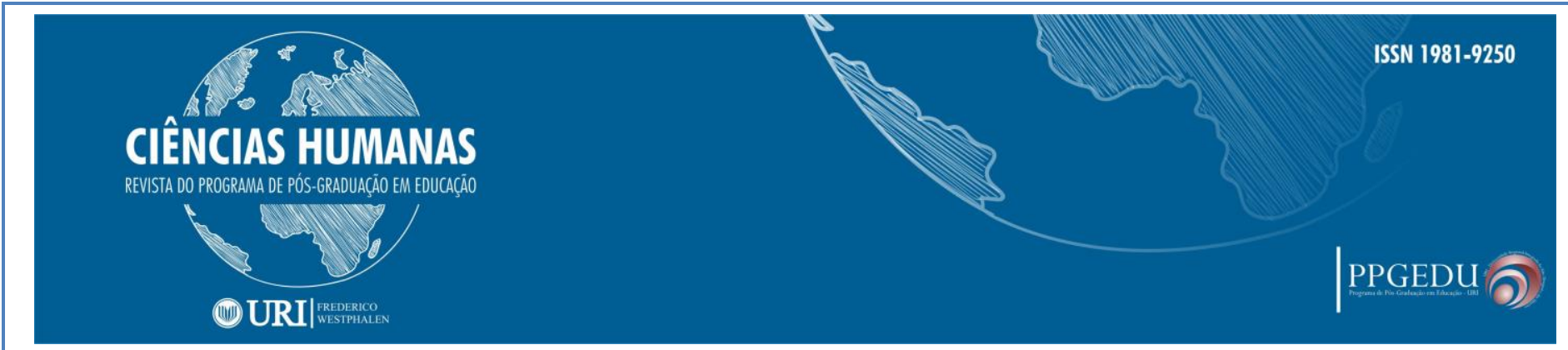

A Educação em Direitos Humanos requer a reflexão em torno das condições de possibilidades, reprodução e justificação das formas simbólicas, sociais e políticas permissivas, que tornam banal a violação da natureza e vulgarizam violações diversas e naturalizam relações humanas de submissão, exclusão, exploração, discriminação, violência, preconceito e perseguição (MAUÉS; WEYL, 2007). Pauta-se ainda nas diretrizes dos Planos Nacionais de Educação em Direitos Humanos (PNEDH). Há contradições nas diferentes concepções e enfoques que embasam a metodologia da Educação, porém, tais divergências têm como ponto em comum a busca por uma nova sociedade, democrática, sem preconceitos, de livre-arbítrio, em que os/as cidadãos/as possam gozar de liberdade, igualdade e solidariedade, princípios básicos da dignidade humana (CANDAU; SACAVINO, 2010). É por estes e tantos outros argumentos que compreendemos que a visão da Escola Sem Partido é distorcida e pode dar margem a diversas interpretações errôneas e retrógradas, ao propor, dentre outros pontos, a extinção de temáticas como Gênero e Política do cotidiano escolar.

Os Direitos Humanos só podem ser assegurados se houver um Estado democrático que entenda que todos/as são livres e iguais em dignidade e direito, porém, diferentes no que se refere às suas individualidades, culturas, crenças, histórias, percepções. Assegurar o direito à Educação significa não só o acesso e permanência nas escolas, mas também a qualidade do ensino e, nisso, se inclui acesso a discussões que abordem a perspectiva da dignidade humana, e tal movimento só é possível trazendo à tona temáticas que envolvem o cotidiano, o subjetivo, o não palpável (FERNANDES; PALUDETO, 2010).

No Brasil, vivemos um período de mudanças significativas no campo da Educação, com corte de verbas, retrocessos a respeito de discussões já consagradas no campo científico e publicações recentes, a exemplo da nova Base Nacional Comum Curricular (BRASIL, 2017) que, de certa forma, não dá a visibilidade necessária a certos conteúdos, a exemplo de Gênero e Diversidade Sexual. Trazem ainda, em alguns pontos e, consequentemente, dão vazão a um retorno ao Positivismo como única ou principal corrente para dar conta do Ensino, à medida que promove o acanhamento de temas politizados e coloca o conteúdo e o mercado de trabalho fim principal da

\begin{tabular}{l|l|l} 
Recebido em: $15 / 04 / 2019$ & Aceito em: 29/04/2019 & Pg. 130 - 145 \\
\hline
\end{tabular}




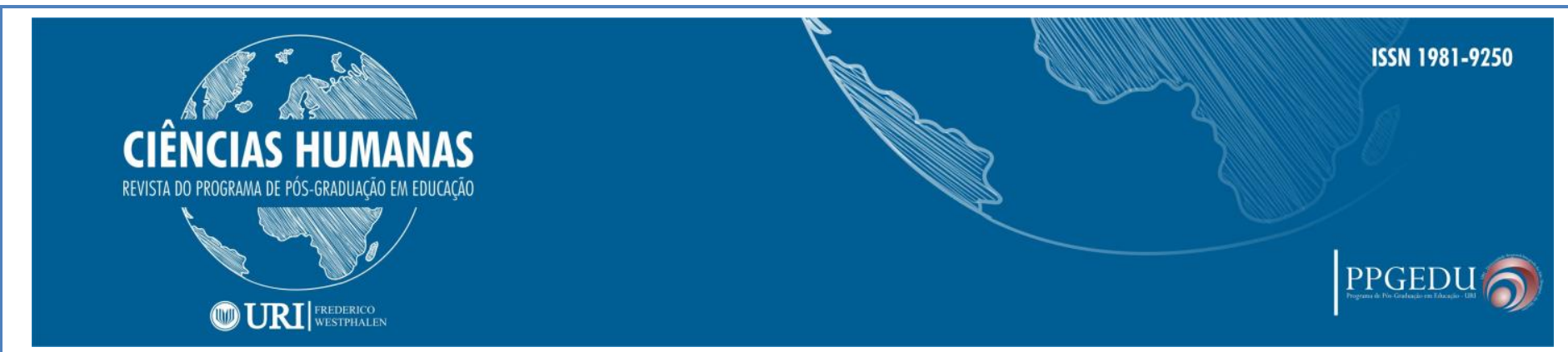

Educação Formal. Dentre os vários argumentos que embasam essa atitude, estão aqueles que se fundamentam em princípios religiosos e calcados em uma moral conservadora, que confunde a perspectiva dos Estudos de Gênero com perversão e ensino inapropriado de conteúdos às crianças.

Cientes de que os Estudos de Gênero trazem consigo discussões importantes do campo dos Direitos Humanos, da emancipação das Minorias e do combate à violência, é que propomos a presente discussão. De antemão, destacamos que, ao esmiuçarmos certos conceitos, pretendemos articulá-los ao campo da saúde, já que não conseguimos visualizar Ética, Direitos Humanos e Gênero deslocados dela.

\section{GÊNERO, SAÚDE E DIVERSIDADE SEXUAL}

Para falarmos em Gênero, Saúde e Diversidade Sexual, precisamos explicar o que queremos dizer com todos esses termos. Imaginamos que os/as leitores/as deste ensaio dão sentidos diversificados para os mesmos em função de suas vivências particulares, da sua cultura, dos grupos aos quais pertencem... Nossa ideia não é desconsiderar esses saberes, mas compartilhar a noção que a Psicologia possui deles. Comecemos pela palavra "gênero".

Ao provocarmos as pessoas a pensarem a respeito de um termo cujo significado é "tão evidente", pode ser que muitas digam: “ora, basta olhar no dicionário que você verá o que significa”. Acontece que, ao nos referirmos a gênero, não estamos nos baseando no sentido dado pelo dicionário à palavra, mas ao sentido dado por pesquisadores/as do campo da Psicologia, da História, da Antropologia, da Filosofia e de tantas outras áreas, cujo foco são os Estudos de Gênero. Essa palavra, nesse contexto, refere-se a um campo de estudos que compreende que as noções de masculino e feminino que vivenciamos e tomamos como naturais ao longo de nossas vidas são construções históricas e discursivas. Em outras palavras, o fato de alguém nascer do sexo masculino não o torna obrigatoriamente homem e o fato de alguém nascer do sexo feminino não o torna obrigatoriamente mulher. Como isso é possível?

\begin{tabular}{l|l|l} 
Recebido em: $15 / 04 / 2019$ & Aceito em: 29/04/2019 & Pg. 130 - 145 \\
\hline
\end{tabular}




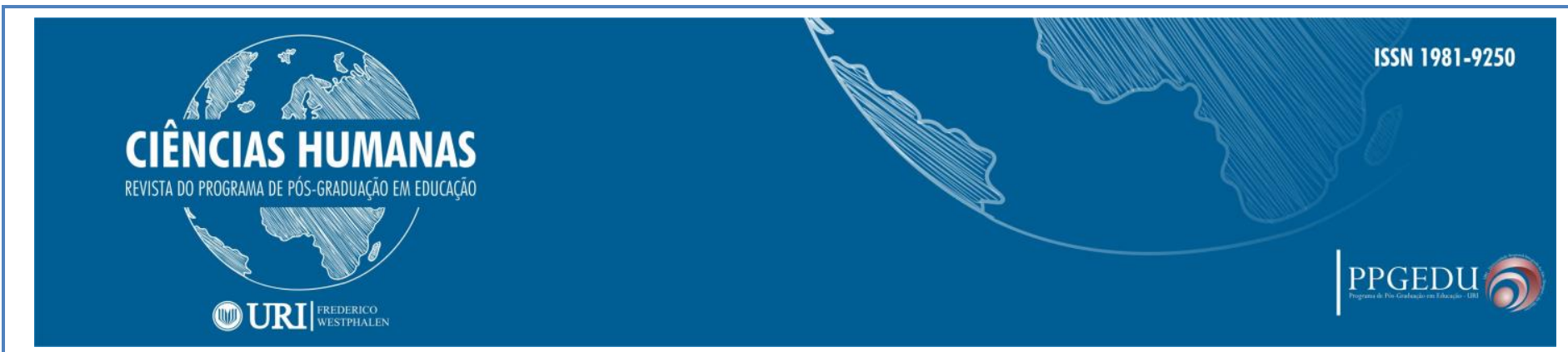

Foi graças ao estudo de muitos/as pesquisadores/as, que revisaram a história da civilização ocidental, a exemplo de Michel Foucault (1998), Elisabeth Badinter (1985), Philippe Àries (1978) e Simone de Beauvoir (2016) que esse e tantos outros conceitos que definem o humano, até então tomados por muita gente como inquestionáveis, passaram a ser questionados. Podemos afirmar, a partir de estudos realizados por Michel Foucault, que a ciência, no decorrer do século XIX, apropriou-se de muitos campos e passou a criar determinados conceitos sobre fenômenos humanos como a loucura, a sexualidade, a educação e etc. Nesse contexto, as Ciência Humanas começam a falar de um padrão de humano, ou seja, elas começam, inspiradas nas discussões realizadas pelas Ciências Naturais, a querer afirmar que existe um jeito único de ser enquanto pessoa e, consequentemente, de exercermos a nossa sexualidade (FOUCAULT, 1998; 2002; 2004; FIGUEIREDO, 2002).

Era muito difícil, naquela época, uma ideia diferente desta se firmar, pois aquele era o século das padronizações, das quantificações. As pessoas procuravam na ciência a resposta para suas dúvidas e, consequentemente, os/as estudiosos/as daquela época, em grande parte, pensaram que poderiam falar de fenômenos humanos do mesmo jeito que se falava de plantas, de pássaros. Entenderam que, se os demais seres vivos tinham um ciclo de vida aparentemente padrão, o humano também teria. Assim, dizer que alguém nasce do sexo masculino, mas não necessariamente seja homem não condizia com o pensamento da época. Foi então que a Ciência em geral desconsiderou - em troca de elevar certos pensamentos a um status "científico" - toda a história da humanidade, e todos os exemplos que ela tinha, nas mais diversificadas civilizações, de que as coisas não eram tão estanques assim, e firmou a ideia de que o sexo define o gênero da pessoa. Logo, se alguém nascesse do sexo masculino, seria homem e se nascesse do sexo feminino, seria mulher.

Entretanto, as pessoas não conseguiram entrar dentro dessa fôrma. Algumas, hoje, até tinham a ilusão de que conseguiram, mas, na realidade, só estavam sendo iludidas por um discurso que não cabia em meio à complexidade da vida humana. Exemplificamos: enxergamos, no dia a dia, tentativas de agrupar homens com homens e mulheres com mulheres, insistindo que essa é uma divisão "natural" e "necessária".

\begin{tabular}{l|l|l} 
Recebido em: $15 / 04 / 2019$ & Aceito em: 29/04/2019 & Pg. 130 - 145 \\
\hline
\end{tabular}




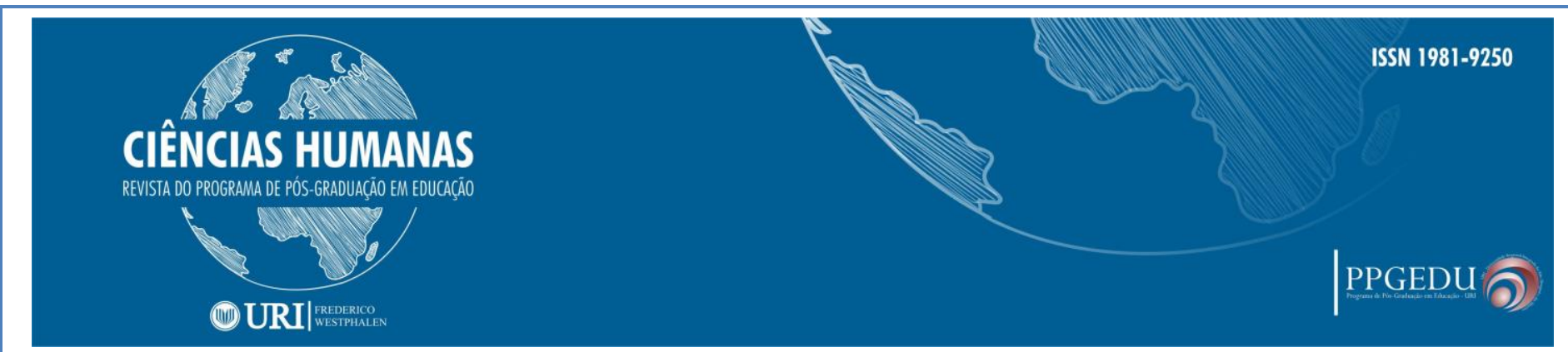

Mas, quando possibilitamos que simplesmente as pessoas vivam juntas, independente do sexo, descobrimos afinidades e diferenças entre elas que independem do sexo, e essa divisão se torna desnecessária, pois, quanto mais separamos as pessoas, mais construímos uma cultura pautada na discriminação e na intolerância às diferenças. Isso não quer dizer que discordamos que as pessoas sejam diferentes. Elas são. Homens são diferentes de mulheres. Homens são diferentes entre homens. Mulheres são diferentes entre mulheres. Homens e mulheres, juntos, são às vezes mais parecidos entre si, por aspectos de ordem individual e/ou cultural, do que entre pessoas do mesmo sexo que o seu e que não compartilham dos mesmos ideais, hábitos e comportamentos.

Agora, quando entramos no assunto diversidade sexual, a discussão vai além. Infelizmente, essa herança das ciências do século XIX destacada acima resultou na patologização de toda e qualquer forma de manifestação da sexualidade e da afetividade que fugisse dos padrões estabelecidos pela época. Em outras palavras, a própria Ciência gerou discriminação e, consequentemente, atrelou comportamentos que fugiam à regra estabelecida como "anormais". Assim, "ter saúde", "ser saudável" passou a ser sinônimo de vivenciar a sexualidade e a afetividade dentro daqueles padrões fechados que discutimos anteriormente.

Ao contrário disso, a Psicologia, hoje, atrelada a outras áreas do conhecimento, entende a saúde como um fenômeno complexo, que não pode ser definido e tomado como universal (CADONÁ; STREY; SCARPARO, 2017). E isso, quem nos diz, é o cotidiano, já que, em meio a ele, as pessoas nomeiam, vivenciam e identificam o que é saudável ou não em comum acordo às suas experiências particulares, coletivas, culturais, e, portanto, se pensarmos em um conceito de saúde fechado e único, não estaremos contemplando toda essa diversidade cultural e individual que também a define.

Se admitirmos que as pessoas vivenciam a realidade das mais variadas formas, e se reconhecermos que as relações sexuais e afetivas se constroem em meio a processos biológicos, sociais e individuais, de forma articulada, não podemos reduzir essas vivências a um padrão universal. É a partir desse ponto de vista que a ciência psicológica reconhece, hoje, que homossexuais, heterossexuais, bissexuais,

\begin{tabular}{l|l|l} 
Recebido em: $15 / 04 / 2019$ & Aceito em: 29/04/2019 & Pg. 130 - 145 \\
\hline
\end{tabular}




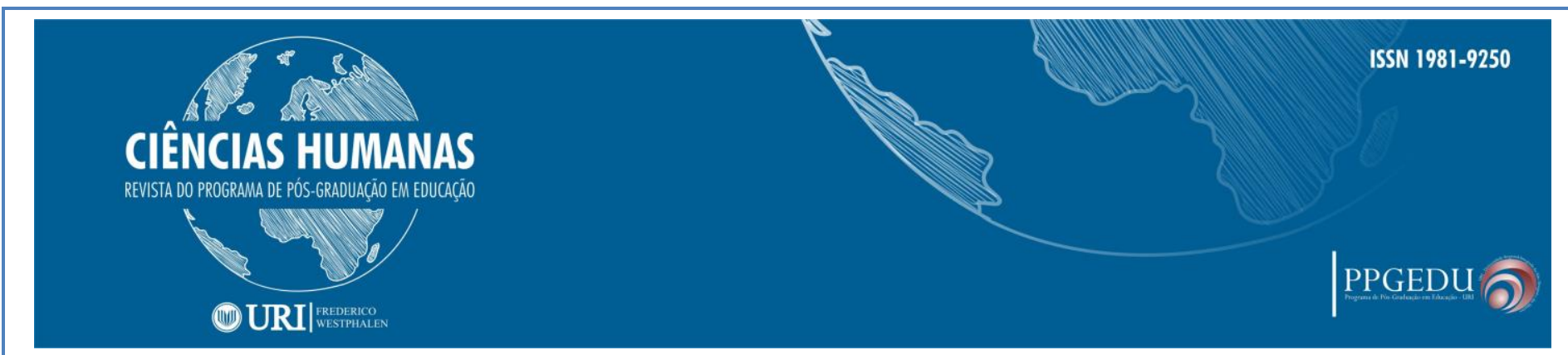

transgêneros, travestis, intersex e tantos outros modos de existir no mundo (falando aqui tanto em orientação sexual, quanto em identidade de gênero e até mesmo em questões de ordem biológica, a exemplo do intersex) não podem ser denominados como anormais, como doentes.

Tomando a ciência psicológica como base, entendemos que, se as pessoas são constituídas em meio a aspectos biológicos, psicológicos e sociais, de forma interrelacional, e que isso vai acontecer de modo diferente para cada um, não podemos definir padrões, pois cada pessoa é única, é uma obra de arte! Tentar "mexer" nessa obra seria matar a sua potência, seria desconsiderar sua trajetória.

À Psicologia, enquanto ciência, não cabe patologizar a orientação sexual e a identidade de gênero das pessoas, tampouco dizer como tem que ser o seu corpo - até porque esta ciência não compreende a homossexualidade, a bissexualidade e tantas outras formas de existir no mundo como doenças (CONSELHO FEDERAL DE PSICOLOGIA, 1999) - mas sim impulsionar a sociedade a pensar em que momento ela passou a colocar essas categorias como um "problema" a ser resolvido e discutido e, pior ainda, "consertado".

\section{ÉTICA, DIREITOS HUMANOS E GÊNERO NO CONTEXTO DA SALA DE AULA}

Pensando em nossa prática docente, observamos a importância de discussões relativas aos Direitos Humanos, Ética e Gênero na formação dos/as futuros/as psicólogos/as, haja vista a necessidade dos/das profissionais da saúde mental participarem da implementação e discussão de políticas públicas. Podemos e devemos discutir tais temas inclusive na prática clínica psicoterápica (modelo tradicional de atendimento do/a psicólogo/a) e também transpor este conceito para a Educação Básica, visto que o indivíduo que busca acolhimento, independente do espaço utilizado para isso, está inserido em um contexto social. A tal modo, ter um olhar macro e, ao mesmo tempo, singular, quando falamos desses assuntos, torna-se uma ferramenta primordial para o desenvolvimento do atendimento psicológico, em uma busca pela não

\begin{tabular}{l|l|l} 
Recebido em: $15 / 04 / 2019$ & Aceito em: 29/04/2019 & Pg. 130 - 145
\end{tabular}




\section{CIÊNCIAS HUMANAS}

REVISTA DO PROGRAMA DE PÓS-GRADUAĞ̈O EM EDUCAĞ̄o

\section{(1) URI|}

dicotomização de vivências, e da superação da forma fragmentada com que as pessoas e os coletivos são investidos no espaço da nossa educação clássica.

Devemos refletir sobre a responsabilidade que temos, enquanto profissionais, para fora das portas de um consultório ou instituição. Tal proteção dessas "paredes" é ilusória. A responsabilidade acerca da vida e das relações nos faz ampliar o olhar para o entorno, para o território, para o cotidiano e as situações imprevistas (CONSELHO FEDERAL DE PSICOLOGIA, 2003).

A intensificação da atuação do/a psicólogo/a em relação aos Direitos Humanos, Ética e Cidadania emerge da preocupação com aspectos sociais e políticos da atual sociedade (BENFATTI; BAYMA; LANDIM, 2013). Instrumentalizar educadores/as quanto à sua importância na formação cidadã significa não abandonar discussões relativas à gênero, raça e crenças nas Escolas. Devemos partir do entendimento de que, ao empoderarmos todos os sujeitos, de todas as idades, para que existam e aprendam na pluralidade, teremos cidadãos/as mais justos e cooperativos. Ao empoderarmos especialmente grupos minoritários, estamos trabalhando pela Educação em Direitos Humanos, quebrando com a ideia meritocrática de que as pessoas devem viver cada uma por si e que, o que conquistam, têm única e exclusivamente a ver com seus esforços.

A Psicologia pretende continuar a discutir tais aspectos, com o objetivo de romper padrões pré-existentes socialmente, e não aceitar qualquer forma de discriminação ou preconceitos. Problematizar tais questões nos parece, à luz de nossa profissão, comprometer-nos eticamente com o ser humano e seus direitos.

Crentes de que nossa formação complementa o olhar pedagógico, e jamais o substitui, compreendemos que as já consolidadas discussões da Psicologia sobre Gênero e Direitos Humanos contribuem para o exercício de uma formação que, ao mesmo tempo em que se preocupa com o conteúdo, reconhece que estes podem conter, de forma transversal, determinados assuntos que aproximam o aprendizado do cotidiano do/a aprendente/a.

\section{ALGUMAS CONSIDERAÇÕES}


Esta discussão, aqui levantada, tem por propósito auxiliar na promoção do debate acerca de temáticas que envolvem a questão dos Direitos Humanos. São muitos os pontos de vista que embasam tais aspectos, embora compreendamos que as bases teóricas, aqui utilizadas, merecem ter maior inserção nos processos de Ensino, no Brasil.

Ressaltamos, mais uma vez, a necessidade de se manter um caráter interdisciplinar acerca das temáticas aqui trazidas, na ideia de que diferentes vozes, sejam elas do campo científico, da comunidade, do alunado ou da família autorizem-se a se manifestar e protagonizar frentes de ação diante das realidades que vivenciamos no cotidiano, e que pedem esse olhar coletivo para o cuidado e respeito às diversidades.

\section{REFERÊNCIAS}

ARIÈS, Philippe. História social da criança e da família. Rio de Janeiro: LTC, 1978.

BADINTER, Elisabeth. Um amor conquistado: o mito do amor materno. Rio de Janeiro: Nova Fronteira, 1985.

BEAUVOUIR, Simone. O segundo sexo: volume 1. Rio de Janeiro: Nova Fronteira, 2016.

BENEVIDES, Maria Victoria. Direitos Humanos: desafios para o século XXI. In: SILVEIRA, R. M. G. et al. (Orgs.). Educação em Direitos Humanos: fundamentos teórico-metodológicos. João Pessoa: Editora Universitária, 2007, p. 335-350.

BENEVIDES, Maria Victoria. Educação para a cidadania e em direitos humanos. In: Encontro Nacional de didática e prática de ensino, 9. Anais. Olhando a qualidade do ensino a partir da sala de aula. Águas de Lindóia: FEUSP, v.2, p.165-177, 1998.

BENFATTI, Xênia Diógenes ; BAYMA, Manuella Bachá Joca ; LANDIM, Ilana Camurça. O papel do psicólogo na promoção e no desenvolvimento de políticas sociais ligadas aos direitos humanos e à cidadania. Revista de Humanidades (UNIFOR), v. 28, p. 94-108, 2013.

BERNARDI, Claudia Maria C. N. A. Formação em Psicologia: Ética, diretrizes curriculares e Direitos Humanos. In: Simpósio Internacional e Fórum Nacional de Educação, 4, 7, 2010, Torres, RS. Disponível em:

\begin{tabular}{l|l|l} 
Recebido em: $15 / 04 / 2019$ & Aceito em: 29/04/2019 & Pg. 130 - 145 \\
\hline
\end{tabular}




\section{(1) URI|}

http://forum.ulbratorres.com.br/2010/palestra texto/PALESTRA\%201.pdf. Acesso em: 01 abr. 2019.

BRASIL. Ministério da Educação. Base Nacional Comum Curricular. Brasília: MEC, 2017.

BRASIL. Constituição da República Federativa do Brasil de 1988. Brasília.

Disponível em:

$<$ http://www.planalto.gov.br/ccivil_03/constituicao/constitui\%C3\%A7ao.htm>. Acesso em: 29 set. 2015 .

BRASIL. Ministério da Educação. Secretaria de Educação Básica. Secretaria de Educação Continuada, Alfabetização, Diversidade e Inclusão. Conselho Nacional da Educação. Diretrizes Curriculares Nacionais Gerais da Educação Básica/ Ministério da Educação. Secretária de Educação Básica. Diretoria de Currículos e Educação Integral. - Brasília: MEC, SEB, DICEI, 2013.

BRASIL. Lei n.9.394, de 20 de dezembro de 1996. Estabelece as diretrizes e Bases da Educação Nacional. Brasília. Disponível em: < http://www.planalto.gov.br/ccivil_03/leis/L9394.htm>. Acesso em 24 jul. 2016.

BRASIL. Parâmetros Curriculares Nacionais. Brasília: MEC/SEF, 1997.

. Problemas de gênero: feminismo e subversão da identidade. Rio de Janeiro: Civilização brasileira, 2008.

CADONÁ, Eliane; STREY, Marlene; SCARPARO, Helena. Conceitos de saúde e cuidado na mídia impressa brasileira: uma análise do ano de 1990. Curitiba: CRV, 2017.

CANDAU, Vera Maria Ferrão. Direito à educação, diversidade e educação em direitos humanos. Educ. Soc., Campinas , v. 33, n. 120, p. 715-726, Set. 2012.

CANDAU, Vera Maria; SACAVINO, Suzana Beatriz. (Orgs.). Educação em direitos humanos: concepções e metodologias. In: FERREIRA, Lúcia de Fátima Guerra; ZENAIDE, Maria de Nazaré Tavares; DIAS, Adelaide Alves (Org.). Direitos humanos na educação superior: subsídios para a educação em direitos humanos na Pedagogia. João Pessoa: UFPB, 2010. p. 113-138.

CANDAU, Vera Maria.; SACAVINO, Suzana Beatriz (Orgs.). Educar em direitos humanos: construir democracia. Rio de Janeiro: DP\&A, 2000.

COLLING, Ana Maria. O corpo que os gregos inventaram. In: STREY, Marlene Neves; CABEDA, Sônia T. L. (orgs). Corpos e subjetividades em exercício interdisciplinar. Porto Alegre: EDIPUCRS, 2004.

\begin{tabular}{l|l|l} 
Recebido em: 15/04/2019 & Aceito em: 29/04/2019 & Pg. $130-145$
\end{tabular}




\section{CIÊNCIAS HUMANAS}

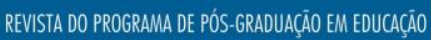

OCURI|

CONSELHO FEDERAL DE PSICOLOGIA. Os Direitos Humanos na prática profissional de psicólogos. Brasília, DF: CFP, 2003. Disponível em:

http://site.cfp.org.br/publicacao/os-direitos-humanos-na-prtica-profissional-dospsicologos/. Acesso em: 01 abr. 2019.

CONSELHO FEDERAL DE PSICOLOGIA. Resolução 001/1999. Estabelece normas de atuação para os psicólogos em relação à questão da Orientação Sexual. Disponível em: https://site.cfp.org.br/wp-content/uploads/1999/03/resolucao1999_1.pdf. Acesso em: 04 abr. 2019.

FERNANDES, Angela Viana Machado; PALUDETO, Melina Casari. Educação e direitos humanos: desafios para a escola contemporânea. Cadernos CEDES, p. 233$249,2010$.

FIGUEIREDO, Luís Cláudio Mendonça; SANTI, Pedro Luiz Ribeiro de. Psicologia, uma (nova) introdução: uma visão histórica da psicologia como ciência. 2. ed. São Paulo: Educ, 2002.

FOUCAULT, Michel. A Psicologia de 1850 a 1950. Ditos e Escritos I. Rio de Janeiro Forense Universitária, 2002.

. História da Sexualidade 2: O uso dos prazeres. Rio de Janeiro: Graal, 1998.

Microfísica do poder. Rio de Janeiro, Graal, 2004.

GERGEN, Kenneth J. O movimento do construcionismo social na psicologia moderna. INTERthesis, $v$. 6, n. 1, p. 299-325, 1985/2009. 484, 2008.

Psicologia social como história. Psicologia \& Sociedade, v. 20, n. 3, p. 475-

GERGEN, Mary M.; GERGEN, Kenneth J. Construcionismo social: um convite ao diálogo. Rio de Janeiro: Instituto Noos, 2010.

GUARESCHI, Pedrinho. Psicologia social crítica: como prática de libertação. Porto Alegre: EDIPUCRS, 2005

GUATTARI, Félix. As três ecologias. Campinas, SP: Papirus, 1990.

LOURO, Guacira. Pedagogias da Sexualidade. In: pedagogias da sexualidade. Belo Horizonte: Autêntica, 2000.

( org). O corpo educado:

MACIEL, Tatiana Santana. Gênero e direitos humanos na educação infantil: Relato de experiência. Revista Organizações e Democracia (online), v. 17, p. 1-10, 2016.

\begin{tabular}{l|l|l} 
Recebido em: $15 / 04 / 2019$ & Aceito em: 29/04/2019 & Pg. 130 - 145
\end{tabular}




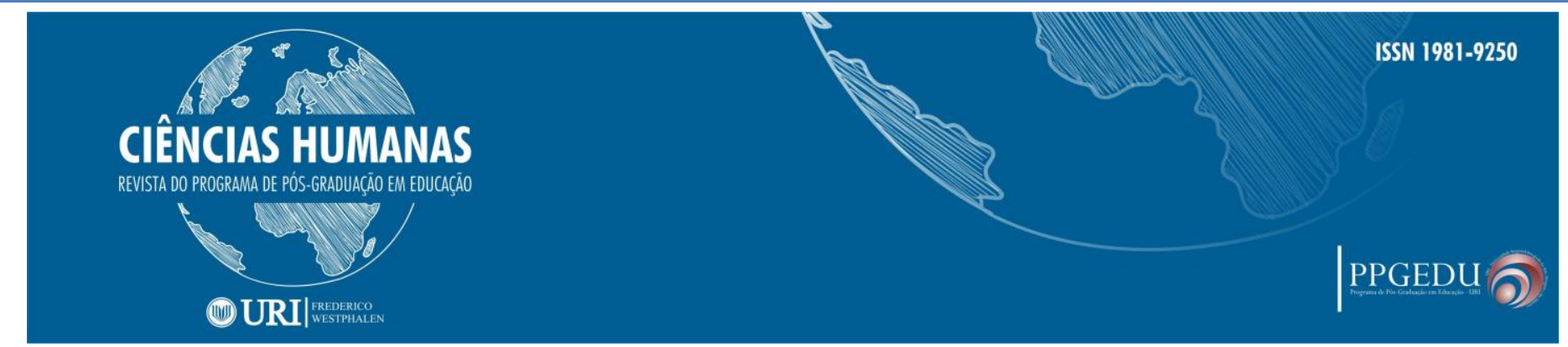

MAUÉS, Antonio; WEYL, Paulo. Fundamentos e marcos jurídicos da educação em Direitos Humanos. In: SILVEIRA, R. M. G. et. al. (Orgs.). Educação em Direitos Humanos: fundamentos teórico-metodológicos. João Pessoa: Editora Universitária, 2007. p. 103-115.

SALIH, Sara. Judith Butler e a teoria Queer. Belo Horizonte: Autêntica, 2013.

SANTOS, Boaventura de Sousa. Um discurso sobre as ciências na transição para uma ciência pós-moderna. Estud. av., São Paulo, v. 2, n. 2, p. 46-71, Ag. 1988 .

STREY, Marlene Neves. Gênero e Ciclos Vitais. In: STREY, Marlene Neves; BOTTON, Andressa; CADONÁ, Eliane; PALMA, Yáskara Arrial. Gênero e Ciclos Vitais: Desafios, Problematizações e Perspectivas. Porto Alegre: EDIPUCRS, 2012. 